TITLE:

The Bunsen-Roscoe reciprocity law in ultraviolet-B-induced mortality of the two-spotted spider mite Tetranychus urticae.

$\operatorname{AUTHOR}(S)$ :

Murata, Yasumasa; Osakabe, Masahiro

CITATION:

Murata, Yasumasa ... [et al]. The Bunsen-Roscoe reciprocity law in ultraviolet-B-induced mortality of the two-spotted spider mite Tetranychus urticae.. Journal of insect physiology 2013, 59(3): 241-247

ISSUE DATE:

2013-03

URL:

http://hdl.handle.net/2433/171233

RIGHT:

(c) 2013 Elsevier Ltd.; この論文は出版社版でありません。引用の際には 出版社版をご確認ご利用ください。; This is not the published version. Please cite only the published version. 


\title{
The Bunsen-Roscoe reciprocity law in ultraviolet-B-induced mortality of the two-spotted spider mite Tetranychus urticae
}

\author{
Yasumasa Murata and Masahiro Osakabe \\ Laboratory of Ecological Information, Graduate School of Agriculture, Kyoto University, \\ Kyoto 606-8502, Japan
}

\begin{abstract}
To determine whether the Bunsen-Roscoe reciprocity law (i.e., the extent of photochemical effects is determined by cumulative irradiance) is applicable to ultraviolet-B (UVB) damage in the twospotted spider mite Tetranychus urticae, egg hatchability and survival of individuals were assessed after irradiation with a UVB lamp using various combinations of intensity and time length. A positive linear correlation between probit mortality and cumulative UVB irradiance was detected in eggs, larvae, teleiochrysalis females, and adult females, regardless of UVB intensity $\left(0.19-0.58 \mathrm{~W} \mathrm{~m}^{-2}\right)$. $\mathrm{LD}_{50}$ values were clearly higher in adult females, followed by teleiochrysalis females, larvae, and eggs. In eggs, reciprocity was obeyed not only at the UVB intensities listed above, but also at very low UVB intensity $\left(0.014-0.023 \mathrm{~W} \mathrm{~m}^{-2}\right)$. Such reciprocity in the negative effects of UVB radiation was also observed for the developmental rate of juveniles and egg production of adult females. However, the $\mathrm{LD}_{50}$ value of eggs obtained using the UVB lamp $\left(0.58 \mathrm{~kJ} \mathrm{~m}^{-2}\right)$ was lower than that elicited by solar UVB radiation in a previous outdoor experiment (about $50 \mathrm{~kJ} \mathrm{~m}^{-2}$ ). These results suggest that a photoreactivation mechanism plays an important role in the survival of this mite under solar radiation.
\end{abstract}

Keywords: UV damage, Cumulative UVB irradiance, Photoreactivation, Acari, Tetranychidae

\section{Introduction}

Ambient ultraviolet (UV) radiation causes deleterious effects in organisms through the induction of cytotoxic DNA lesions, for example, cyclobutane-pyrimidine dimers (CPDs) and 6-4 photoproducts (Sinha and Häder, 2002), and the production of reactive oxygen species (Jurkiewicz and Buettner, 1994). Recent literature has documented the harmfulness of solar and artificial UV radiation to plant-dwelling mites, such as the herbivorous twospotted spider mite Tetranychus urticae Koch (Ohtsuka and Osakabe, 2009; Suzuki et al., 2009), as well as predaceous phytoseiid mites (Ohtsuka and Osakabe, 2009; Onzo et al., 2010; Tachi and Osakabe, 2012). Of the range of UV wavelengths, damage to T. urticae is induced by ultraviolet-B (UVB, 280-315 nm wavelengths; Sakai and Osakabe, 2010). Sakai and Osakabe (2010) concluded that escape from UVB damage was the main factor determining the typical location of T. urticae on the lower leaf surfaces of host plants.

The Bunsen-Roscoe reciprocity law (hereafter, the reciprocity law) states that as long as the product of irradiance and the time of exposure is the same the photochemical effect will be the same (Dworkin, 1958); i.e., the extent of photochemical effects is determined by cumulative irradiance $\left(\mathrm{J} \mathrm{m}^{-2}\right)$ [= irradiance $\left(\mathrm{W} \mathrm{m}^{-2}\right) \times$ irradiation period (s)]. The reciprocity

* Corresponding author.

Masahiro Osakabe

E-mail: mhosaka@kais.kyoto-u.ac.jp

Tel.: +81 75753 2267; Fax: +81757532267 
law might also be applicable to UV damage in organisms, e.g., the amount of DNA lesions in an aquatic arthropod, Daphnia sp. (Connelly et al., 2009), and the extent of disinfection of the airborne bacterium Serratia marcescens (Riley and Kaufman, 1972). Reciprocity in survivorship under UVB radiation has also been demonstrated in shrimp zoea (Wübben, 2000), early life stages of sea urchin (Nahon et al., 2009) and fish eggs (Kouwenberg et al., 1999). However, mortality of shrimp zoea after UVB irradiation at low intensity $\left(0.2 \mathrm{~W} \mathrm{~m}^{-2}\right)$ diverged from the reciprocity law, which had been upheld under radiation at higher irradiances (Wübben, 2000). Similar divergence from reciprocity in UVB damage was also found for several cases of aquatic animals (Cywinska et al., 2000). Therefore, applicability of the reciprocity law to UV damage in organisms is still disputable.

Most previous studies in this field have been conducted using aquatic animals. Thus far, little information about the reciprocity law in UVB damage of terrestrial animals has been reported. Sakai et al. (2012) found that the hatchability of T. urticae eggs experimentally exposed to solar UVB radiation was negatively correlated with cumulative UVB irradiance but not with UVB intensity. Although intense UVB radiation in summer was expected to exert the greatest effect on survival of T. urticae (e.g., Barcelo, 1981), egg hatchability was lowest in April (11\%) and increased almost linearly until October (92\%; Sakai et al., 2012).

In this study, we aimed to elucidate whether the reciprocity law is applicable to UVB damage of T. urticae. We examined egg hatchability and survival of larvae, teleiochrysalises, and adults after irradiation with UVB at various combinations of intensity and time lengths using a UVB lamp. Effects on egg production and developmental rate were also evaluated.

\section{Materials and methods}

\subsection{Mites}

The common polyphagous spider mite $T$. urticae is an economically important agricultural pest with a worldwide distribution. The population of $T$. urticae used in this study had been cultured in the laboratory on potted kidney bean plants at $25-28^{\circ} \mathrm{C}$ for at least 6 years. Mite populations from several different localities in Japan had been added to the cultures.

\subsection{UVB irradiation}

UVB irradiation was performed at $25^{\circ} \mathrm{C}$ in the laboratory, whose interior was illuminated by fluorescent lamps. Eggs or mites on leaf disks in Petri dishes were placed on four shelves located at different distances $(0.45,0.85,1.35$, and $1.75 \mathrm{~m})$ from an overhead UVB lamp (YGRFX21701GH; Panasonic Co., Osaka, Japan) affixed at the top of a steel rack (1.9 $\mathrm{m}$ high $\times 0.6 \mathrm{~m}$ width $\times 0.6 \mathrm{~m}$ depth). The intensities of UVB $(280-320 \mathrm{~nm})$ received by the Petri dishes on the shelves were 0.19 (UVA+UVB: 0.27), $0.31(0.45), 0.58(1.0)$, and $1.55(2.8) \mathrm{W}$ $\mathrm{m}^{-2}$, respectively $\left(\mathrm{X}_{1}\right.$ Optomerter; Gigahertz-Optik Inc., Newburyport, MA). The highest solar UVB irradiances at ground level in Japanese main islands over seasons are around $2 \mathrm{~W}$ $\mathrm{m}^{-2}$ (Nozawa et al., 2007, 2010). The UVB irradiances used in this study was thus within the ambient solar UVB radiation in Japan. The frame of the shelves (steel rack) was covered with UV-opaque film $(0.1 \mathrm{~mm}$ thick polyvinyl chloride film, Cutaceclean Kirinain; MKV Platech Co. Ltd., Tokyo, Japan) that filtered out UV. Petri dishes assigned as controls were placed on an adjoining shelf outside of the UV opaque film (UVB irradiance $=0 \mathrm{~W} \mathrm{~m}^{-2}$ ).

The output of the UV lamp peaked at a wavelength of $310 \mathrm{~nm}$. Because the laboratory interior was illuminated with fluorescent lamps during the UVB irradiation, data from this experiment potentially contain the effects of photoreactivation. The spectrum of relative intensity was measured using a spectrometer (UFV-VIS F; Spectra Co-op Co., Tokyo, Japan; Fig. 1). After UVB irradiation, the Petri dishes were kept in the laboratory at $25^{\circ} \mathrm{C}$ and $16: 8 \mathrm{~h}$ $\mathrm{L}: \mathrm{D}$ light cycles (fluorescent lights were turned on at 07:00 h and off at 23:00 h). 


\subsection{Mite preparation and observation after UVB irradiation}

\subsubsection{Effects on egg hatchability}

We prepared eight Petri dishes $(9 \mathrm{~cm}$ in diameter $)$. Four kidney bean leaf disks $(2 \times 2 \mathrm{~cm})$ were placed on water-soaked cotton in each of the Petri dishes. Five adult T. urticae females were introduced onto each leaf disk. These Petri dishes were placed in the laboratory $\left(25^{\circ} \mathrm{C}\right.$, 16:8 $\mathrm{h} \mathrm{L}: \mathrm{D})$. After $24 \mathrm{~h}$, the adult females were removed, and eggs laid on the leaf disks were counted. Two Petri dishes were then placed on each of three shelves for irradiation at $0.19,0.31$, and $0.58 \mathrm{~W} \mathrm{~m}^{-2}$ of UVB radiation, and the remaining two dishes were placed on the adjoining shelf as controls $\left(0 \mu \mathrm{W} \mathrm{cm}{ }^{-2}\right)$. We immediately exposed these eggs to UVB radiation for 15,30 , 60 , or $90 \mathrm{~min}$.

Using the same procedure, eggs were also exposed to treatments irradiated with 0 (control), 0.31 , and $0.58 \mathrm{~W} \mathrm{~m}^{-2} \mathrm{UVB}$ for $10 \mathrm{~min}$, and with $0,0.19$, and $0.31 \mathrm{~W} \mathrm{~m}^{-2}$ for $120 \mathrm{~min}$.

A series of treatments was performed once. The numbers of eggs used for each combination of UVB intensity and irradiation time length (two Petri dishes containing eight leaf disks) were 283-453 in total (20-63 eggs per leaf disk except one leaf disk assigned for 0 $\mu \mathrm{W} \mathrm{cm}{ }^{-2}$ for 10 min exposure, on which only three eggs were available because four adult females had escaped from a leaf disk during the oviposition period).

After exposure to UVB radiation, the Petri dishes were returned to the laboratory where they had been reared before treatment $\left(25^{\circ} \mathrm{C}, 16: 8 \mathrm{~h} \mathrm{~L}: \mathrm{D}\right)$. Hatchability was checked on day 6 after exposure, as we had previously confirmed that few eggs hatched after 6 days post-exposure.

Assuming that the UVB damage obeyed the reciprocity law, to clarify the damage threshold by the intensity of UVB radiation, we additionally tested the effects of weak UVB irradiation on egg hatchability. Low-intensity treatments were performed by irradiation with 0 (control) and $0.023 \mathrm{~W} \mathrm{~m}^{-2}$ for $10 \mathrm{~h}, 0$ and $0.014 \mathrm{~W} \mathrm{~m}^{-2}$ for $217 \mathrm{~min}$, and 0 and $0.018 \mathrm{~W} \mathrm{~m}^{-2}$ for $284 \mathrm{~min}$ and $471 \mathrm{~min}$. For the low-intensity treatment, the overhead UVB lamp was covered with a black metal mask made of a perforated metal mesh [Perforated Metal No. $16(\varphi 2 \times 3.5 \mathrm{P}$ staggered perforation; 29.6\% open), Metaltech Co., Tokyo]. Two Petri dishes prepared using the same procedure described above were set on the shelf at $1.75 \mathrm{~m}$ from the UVB lamp, and another two Petri dishes were placed on the adjoining shelf as controls $\left(0 \mathrm{~W} \mathrm{~m}^{-2}\right)$.

A series of treatments was performed once. The numbers of eggs used for each combination of UVB intensity and irradiation time length (two Petri dishes containing eight leaf disks) were 376-571.

After exposure to UVB radiation, egg hatchability was determined using the procedure described above. In the data analysis, mortality rates from the low- and high-intensity (described above) treatments were compared (see section 2.4).

\subsubsection{Effects on larvae}

Two kidney bean leaf disks $(2 \times 2 \mathrm{~cm})$ were placed on water-soaked cotton in each of four Petri dishes for each batch. Five adult T. urticae females were introduced onto each leaf disk in the laboratory $\left(25^{\circ} \mathrm{C}, 16: 8 \mathrm{~h} \mathrm{~L}: \mathrm{D}\right)$. After $24 \mathrm{~h}$, adult females were removed. Two days later (day 2 after the removal of adult females), we checked egg status and removed hatched larvae if present. On day 3, we counted the number of larvae hatched within $24 \mathrm{~h}$ and removed unhatched eggs. One Petri dish (two leaf disks) was placed on each of three shelves, 0.19, 0.31, and $0.58 \mathrm{~W} \mathrm{~m}^{-2}$, and on the adjoining shelf as a control $\left(0 \mathrm{~W} \mathrm{~m}^{-2}\right)$. We then exposed these larvae to UVB radiation for 30,45 , or $60 \mathrm{~min}$.

Using the same procedure, larvae were also irradiated using treatments with 0 (control) and $0.58 \mathrm{~W} \mathrm{~m}^{-2}$ for $15 \mathrm{~min}$; 0 and $0.31 \mathrm{~W} \mathrm{~m}^{-2}$ for $90 \mathrm{~min} ; 0,0.19$, and $0.31 \mathrm{~W} \mathrm{~m}^{-2}$ for $120 \mathrm{~min}$; and with 0 and $0.19 \mathrm{~W} \mathrm{~m}^{-2}$ for $180 \mathrm{~min}$.

A series of treatments was performed twice. The numbers of larvae used for each 
combination of UVB intensity and irradiation time length (two Petri dishes containing four leaf disks) were 49-95 in total (21-48 larvae per treatment).

After exposure to UVB radiation, larvae were individually transferred to newly prepared leaf disks $(1.5 \times 1.5 \mathrm{~cm})$ on water-soaked cotton in Petri dishes in the laboratory $\left(25^{\circ} \mathrm{C}, 16: 8 \mathrm{~h}\right.$ L:D). We then checked the survival rate, developmental stage, and sex of individuals that attained maturity every day until all individuals had developed to adulthood or died (day 9). Individuals remaining at a particular chrysalis stage for more than 5 days were judged to be dead.

\subsubsection{Effects on teleiochrysalis females}

One kidney bean leaf disk $(4 \times 4 \mathrm{~cm})$ was placed on water-soaked cotton in each of four Petri dishes. From 30 to 32 teleiochrysalis females (quiescent stage of deutonymph just before the last molt to adulthood) were introduced onto each leaf disk. One Petri dish was placed on each of three shelves, $0.19,0.31$, and $0.58 \mathrm{~W} \mathrm{~m}^{-2}$, and on the adjoining shelf as a control $(0 \mathrm{~W}$ $\mathrm{m}^{-2}$ ). We then exposed these teleiochrysalis females to UVB radiation for 60,120 , or $180 \mathrm{~min}$.

Using the same procedure, teleiochrysalis females were also irradiated using treatments with 0 (control), 0.58 , and $1.55 \mathrm{~W} \mathrm{~m}^{-2}$ for $30 \mathrm{~min}$, and with 0 (control), 0.19 , and $0.31 \mathrm{~W} \mathrm{~m}^{-2}$ for $240 \mathrm{~min}$.

A series of treatments was performed once. The numbers of teleiochrysalis females used for each combination of UVB intensity and irradiation time length (one leaf disk) were 29-32.

After exposure to UVB radiation, we removed individuals that had molted during exposure to UVB radiation. These females were reared in the laboratory $\left(25^{\circ} \mathrm{C}, 16: 8 \mathrm{~h} \mathrm{~L}: \mathrm{D}\right)$. The proportion of molting individuals was checked 3 days after exposure because we preliminary confirmed that few individuals molted after 3 days post-exposure.

\subsubsection{Effects on adult females}

One kidney bean leaf disk $(4 \times 4 \mathrm{~cm})$ was placed on water-soaked cotton in each of four Petri dishes. Twenty teleiochrysalis females were introduced onto each leaf disk. To raise the relative humidity $(\mathrm{RH})$ on the leaves, the Petri dishes were covered with transparent plastic lids. Under humid conditions, tetranychid mites in the quiescent stage delay molting (Ikegami et al., 2000). After 2 days (day 0), the lids were removed and most adult virgin females emerged within $30 \mathrm{~min}$. Three days later (day 3), we counted newly emerged adult females. One Petri dish was placed on each of three shelves, $0.31,0.58$, and $1.55 \mathrm{~W} \mathrm{~m}^{-2}$, and on the adjoining shelf as a control $\left(0 \mathrm{~W} \mathrm{~m}^{-2}\right)$. We then exposed these adult females to UVB radiation for $6 \mathrm{~h}$.

Using the same procedure, adult females were also irradiated using treatments with 0 (control), and $1.55 \mathrm{~W} \mathrm{~m}^{-2}$ for 2 and $10 \mathrm{~h}$, and with $0,0.31$, and $0.58 \mathrm{~W} \mathrm{~m}^{-2}$ for 14 and $24 \mathrm{~h}$.

A series of treatments was performed three times. The numbers of adult females for each combination of UVB intensity and irradiation time length (three Petri dishes containing three leaf disks) were 41-60 in total (13-20 females per treatment except two leaf disks assigned for $0 \mu \mathrm{W} \mathrm{cm}{ }^{-2}$ for $14 \mathrm{~h}$ and $24 \mathrm{~h}$ exposure, on which 4 and 9 adult females, respectively, were available because of excessive failure to molt).

After exposure to UVB radiation, adult females were individually transferred to newly prepared leaf disks $(1.5 \times 1.5 \mathrm{~cm})$ on water-soaked cotton in Petri dishes in the laboratory $\left(25^{\circ} \mathrm{C}, 16: 8 \mathrm{~h} \mathrm{~L}: \mathrm{D}\right)$. We checked the survival rates after 3 days (day 6) because we preliminary confirmed that individuals died due to UVB damage were clearly distinctive from living mites. Females escaped from leaf disks were included in the number of dead individuals. The number of eggs laid on each leaf disk was also checked on day 3. 


\subsection{Data analysis}

\subsubsection{Regression of mortality on cumulative UVB irradiance and $L D_{50}$}

Mortality in each treatment was corrected following Abbott's formula (Abbott, 1925),

$M=\{(Y-X) /(1-X)\} \times 100$,

where $M, X$, and $Y$ represent the \%-corrected mortality, the natural (control) death rate of individuals (eggs), and the death rate of individuals (eggs) exposed to UVB radiation, respectively, in each treatment. For this calculation, the number of individuals (eggs) on leaf disks was pooled in each treatment (no replication experiment).

The corrected mortalities were transformed to probits except for data on 0 or $100 \%$ mortality. To evaluate the effects of UVB intensity on mortality, the data set for each developmental stage was used in an analysis of covariance (ANCOVA) using R (version 2.14.0; R Development Core Team, 2009) following Aoki (2011). In ANCOVA, the cumulative UVB irradiances, mortality probits and UVB intensities were used as independent variables, dependent variables, and group variables, respectively. If no significant differences were detected in slopes and mean mortalities among different intensities, linear regression analysis was applied to the data set using the "lm" module of $\mathrm{R}$. $\mathrm{LD}_{50}$ values and associated standard errors were obtained using the "dose.p" module in the package MASS, and 95\% confidence intervals of the $\mathrm{LD}_{50}$ values were calculated based on the $97.5 \%$ point of cumulative probability distribution in the $\mathrm{t}$-distribution predicted using the "qt" module of $\mathrm{R}$.

\section{4. 2. Analysis of the effects of low intensity UVB on egg mortality}

To evaluate whether reciprocity was applicable to the effects of low-intensity irradiation (0.014-0.023 $\mathrm{W} \mathrm{m}^{-2}$ ), we performed a generalized linear model (GLM; Gaussian) analysis using probit mortality data sets for eggs, with the UVB irradiation treatment categorically divided into low intensity and high intensity $\left(0.19-0.58 \mathrm{~W} \mathrm{~m}^{-2}\right)$. The probit mortality data sets were obtained using the procedure described above (see section 2.4.1).

\section{4. 3. Analysis of the effects of UVB irradiation on the developmental rate}

The effects of UVB intensity on the developmental rate were evaluated by ANCOVA using R following Aoki (2011). In ANCOVA, the cumulative UVB irradiances, developmental days, and UVB intensities were used as independent variables, dependent variables, and group variables, respectively. If no significant differences were detected in slopes and mean mortalities among different intensities, linear regression analysis was applied to data sets with all UVB intensities combined, except controls $\left(0 \mathrm{~W} \mathrm{~m}^{-2}\right)$, using the " $1 \mathrm{~m}$ " module of R.

\section{4. 4. Analysis of the effects of UVB irradiation on egg production of adult females}

For the analysis of egg production, linear regression analysis was applied to the data sets with all UVB intensities combined, except for females with no egg production, using the "lm" module of R. We did not apply ANCOVA because the sample sizes for individual intensities were too low.

\section{Results}

\section{1. Mortality regression on cumulative $U V B$ irradiance and $L D_{50}$}

Mortality increased with cumulative doses of irradiation, and no differences in mortality were observed among UVB intensities for eggs, larvae, and adult females (Fig. 2a, b, d, respectively). Larvae were not likely to be affected by UVB irradiation in terms of their behavior and activity after exposure to UVB radiation, and most entered the protochrysalis stage normally, even at the higher cumulative UVB irradiance. However, many individuals 
died during the protochrysalis stage or failed to molt to the protonymphal stage and died. In contrast, the mortality of teleiochrysalis females also increased with increasing cumulative UVB irradiance but reached a plateau at $2.8 \mathrm{~kJ} \mathrm{~m}^{-2}$ (Fig. 2c).

ANCOVA using probit mortalities revealed that neither the slope nor average mortality significantly differed among UVB intensities for all life stages (egg, slope: $\mathrm{F}_{[2,8]}=3.2492, \mathrm{P}=$ 0.09270, average: $\mathrm{F}_{[2,10]}=2.2925, \mathrm{P}=0.1515$; larva, slope: $\mathrm{F}_{[2,4]}=1.1567, \mathrm{P}=0.4014$, average: $\mathrm{F}_{[2,6]}=0.01909, \mathrm{P}=0.9811$; teleiochrysalis female, slope: $\mathrm{F}_{[2,6]}=2.8399, \mathrm{P}=0.1356$, average: $\mathrm{F}_{[2,8]}=0.1893, \mathrm{P}=0.8312$ ), except for adult females, which were not analyzed using ANCOVA.

We observed strong positive linear correlations between probit mortality and cumulative UVB irradiance for eggs, larvae, and adult females (Fig. 3). The $\mathrm{LD}_{50}$ value was highest in adult females, followed by larvae and eggs (Table 1). Although we detected a significant positive linear correlation for teleiochrysalis females, both the slope and coefficient of determination $\left(\mathrm{R}^{2}\right)$ were much smaller than those observed for the other developmental stages, causing the $\mathrm{LD}_{50}$ value to be equivalent to that in larvae (versus adult females; Fig. 3, Table 1).

\subsection{Reciprocity in mortality of eggs exposed to low-intensity UVB radiation}

The mortalities of eggs exposed to UVB radiation at low intensity $\left(0.014-0.023 \mathrm{~W} \mathrm{~m}^{-2}\right)$ also increased with cumulative UVB irradiance and were distributed around the linear regression line for eggs exposed to UVB radiation at high intensity $\left(0.19-0.58 \mathrm{~W} \mathrm{~m}^{-2}\right.$; Fig. 4). A GLM analysis revealed that the UVB intensity to which eggs were exposed (low or high) did not significantly affect egg mortality (Table 2), suggesting that reciprocity is also applicable when eggs are exposed to UVB radiation at very low intensity.

\subsection{Effects of UVB irradiation on larvae and subsequent developmental rates}

In individuals that had developed from larvae to adulthood after exposure to UVB radiation at the larval stage, no differences were observed in the number of developmental days among UVB intensities for either females or males (ANCOVA: female, slope: $F_{[2,3]}=0.1275$, $\mathrm{P}=0.8848$, average: $\mathrm{F}_{[2,5]}=2.7394, \mathrm{P}=0.1573$; male, slope: $\mathrm{F}_{[2,3]}=0.2295, \mathrm{P}=0.8077$, average: $F_{[2,5]}=1.3624, P=0.3371$; Fig. 4$)$. Because only one female and one male developed to adulthood, data for UVB intensity at $0.31 \mathrm{~W} \mathrm{~m}^{-2}$ for $90 \mathrm{~min}\left(1.674 \mathrm{~kJ} \mathrm{~m}^{-2}\right)$ exposure were excluded from the data analysis. The developmental period was prolonged with increasing cumulative UVB irradiance. We observed a significant positive linear relationship between cumulative UVB irradiance and developmental period, except for the control $\left(0 \mathrm{~W} \mathrm{~m}^{-2}\right)$, in both females and males (males: $y=1.2454 x+4.8320, R^{2}=0.6292, P=0.006564$; females: $y=$ $2.2946 x+4.5381, R^{2}=0.832, P=0.0003769$ ). However, the $y$-intercept ( 4.8 and 4.5 days in males and females, respectively) was obviously smaller than that for the developmental period of individuals in controls $\left[0 \mathrm{~W} \mathrm{~m}^{-2}, 5.4 \pm 0.1\right.$ (SE) and $5.8 \pm 0.1$ days in males and females, respectively; Fig. 5]. Using the linear regression, the cumulative UVB irradiance corresponding to the developmental periods in controls was back-calculated to be 0.48 and $0.53 \mathrm{~kJ} \mathrm{~m}^{-2}$ in males and females, respectively. Therefore, cumulative UVB irradiance below $0.5 \mathrm{~kJ} \mathrm{~m}^{-2}$ may have no to slight negative effects on the rate of subsequent juvenile development, regardless of the intensity of UVB radiation. Consequently, the reciprocity law was upheld in juvenile development when cumulative UVB irradiance exceeded $0.5 \mathrm{~kJ} \mathrm{~m}^{-2}$. However, negative effects did not occur below $0.5 \mathrm{~kJ} \mathrm{~m}^{-2}$.

\subsection{Effects of UVB irradiation on adult females and subsequent egg production}

In adult females, egg production was reduced with increasing cumulative UVB irradiance (Fig. 6). Females that survived after exposure to $0.58 \mathrm{~W} \mathrm{~m}^{-2}$ for $24 \mathrm{~h}\left(50.112 \mathrm{~kJ} \mathrm{~m}^{-2}\right)$ of UVB radiation $(n=4)$ and laid no eggs were excluded from Fig. 6 and the linear regression analysis. 
The number of eggs did not remarkably differ among UVB intensities at the corresponding cumulative irradiance. We detected a significant negative linear relationship between cumulative UVB irradiance and egg production using the combined data set $(y=-1.3282 x+$ $44.8954, \mathrm{R}^{2}=0.906, \mathrm{P}=0.0001686$; Fig. 6). Therefore, the reciprocity law was upheld for egg production.

\section{Discussion}

We tested the idea that cumulative irradiance is more detrimental than simply being exposed to a higher intensity, that is, the Bunsen-Roscoe reciprocity law, in the biological effects of UVB radiation on a terrestrial phytophagous mite. To evaluate this idea, we compared the effects between intensity and cumulative irradiance of UVB radiation on mortality and performance of $T$. urticae. As a result, mortality after exposure to UVB radiation increased with cumulative UVB irradiance, regardless of UVB intensity, in the eggs, larvae, teleiochrysalises, and adult females of T. urticae. Moreover, juvenile development and egg production were also negatively affected by cumulative UVB irradiance $\left(>0.5 \mathrm{~kJ} \mathrm{~m}^{-2}\right.$ for juvenile development), regardless of UVB intensity. These results are consistent with those of Sakai et al. (2012), who found that the hatchability of $T$. urticae eggs experimentally exposed to solar UVB radiation was negatively correlated with cumulative UVB irradiance but not with UVB intensity.

Divergence from the reciprocity law was observed in aquatic animals under UVB radiation at low intensity such as $0.2-0.4 \mathrm{~W} \mathrm{~m}^{-2}$ (Cywinska et al., 2000; Wübben, 2000), suggesting a presence of damage threshold by UVB intensity. In contrast, reciprocity was applicable to mortality of $T$. urticae eggs even if those were exposed to very low-intensity UVB radiation $\left(0.014-0.023 \mathrm{~W} \mathrm{~m}^{-2}\right)$. Instead, we found damage threshold cumulative UVB irradiances for juvenile performance; the developmental rate was not affected by UVB irradiation below 0.5 $\mathrm{kJ} \mathrm{m}^{-2}$. Therefore, we concluded that the reciprocity law is applicable to UVB damage in $T$. urticae. This study may be the first report demonstrating the reciprocity law for UVB damage in a terrestrial animal. Such difference in thresholds between aquatic and terrestrial animals might be caused by the difference in the presence/absence of surrounding water.

Although the significant positive linear correlation was observed between cumulative UVB irradiance and probit mortality in T. urticae teleiochrysalis females, the $R^{2}$ value and slope of the regression line were small. In contrast, larvae exposed to UVB radiation died primarily during the protochrysalis stage or later when failing to molt to protonymphs. These results suggest that the physiological mechanism for ecdysis was vulnerable to damage from UVB. Moreover, vulnerability during chrysalis stages may differ depending on the phase preceding molting, which may be why the vulnerability of teleiochrysalis was diverse and more similar to that of larvae than of adult females, despite a larger body size as teleiochrysalises than as larvae.

In regard to solar radiation, daily cumulative UVB irradiance is highest in summer (generally July and August) and lowest in winter (December and January) in the midlatitudes of the Northern Hemisphere. According to the Solar Radiation and Weather Monitoring Project at Kyoto Women's University (http://www.cs.kyoto-wu.ac.jp/ konami/climate/index.shtml), maximum and minimum daily solar UVB irradiance were 21.8 and $4.3 \mathrm{~kJ} \mathrm{~m}^{-2}$, respectively, in Kyoto, Japan (345ㅇ' $\left.\mathrm{N}, 135^{\circ} 47^{\prime} \mathrm{E}\right)$ during 2009-2010. Therefore, the maximum daily irradiance was close to the $\mathrm{LD}_{50}$ value of adult females, and even minimum daily irradiance exceeded the $\mathrm{LD}_{50}$ values of eggs, larvae, and teleiochrysalis females obtained in the laboratory. However, Sakai et al. (2012) estimated that the $\mathrm{LD}_{50}$ of $T$. urticae eggs caused by solar UVB radiation was about $50 \mathrm{~kJ} \mathrm{~m}^{-2}$. This value is 86 times the $\mathrm{LD}_{50}$ for eggs $\left(0.58 \mathrm{~kJ} \mathrm{~m}^{-2}\right)$ and twice that for adult females $\left(26.12 \mathrm{~kJ} \mathrm{~m}^{-2}\right)$ determined in our laboratory experiments using a UV lamp. 
Such differences between damage by the UV lamp and solar UV radiation also likely occur for effects on the egg production of adult females. Sakai and Osakabe (2010) tested irradiation effects on egg production by exposing T. urticae adult females to solar UV radiation under UV-transparent and UV-opaque film. They observed a reduction in the egg production of females exposed to solar UV radiation (under UV transparent film; Sakai and Osakabe 2010). However, the reduction was less than $30 \%$ of that observed for egg production by females under UV-opaque film, despite cumulative UVB radiation values for UV-transparent and UV-opaque film being 84.6 and $49.7 \mathrm{~kJ} \mathrm{~m}^{-2}$, respectively. In this study, the cumulative UVB irradiance at which egg production is zero, as calculated from the regression line, is $33.8 \mathrm{~kJ}$ $\mathrm{m}^{-2}$. In actuality, most adult female individuals died and the survivors laid no eggs after exposure to $50.112 \mathrm{~kJ} \mathrm{~m}^{-2} \mathrm{UVB}$ radiation.

The potential mechanism causing such variation in $\mathrm{LD}_{50}$ values between laboratory and field studies may be the photoenzymatic repair of UVB-induced DNA damage (Kalthoff, 1975; Sinha and Häder, 2002; Macfadyen et al., 2004). In fact, Santos (2005) has suggested such a function of photoreactivation in T. urticae adult females. Moreover, recent coding sequence (CDS) analyses have revealed the presence of several cyclobutane pyrimidine dimer (CPD) photolyase genes in the T. urticae genome (Grbić et al., 2011). Photoenzymatic repair of DNA lesions with the aid of photolyase is one of the most important repair mechanisms that frequently occurs in many organisms (Sinha and Häder, 2002; Weber, 2005). Our experimental condition also included some UVA and visible light radiation. However, the ratio of UVA and visible lights in the spectrum was extremely smaller than those in solar radiation, suggesting that photoenzymatic repair is likely to play more effectively under solar radiation than our experimental condition.

Consequently, our findings suggest that such a photoreactivation mechanism plays an important role for the survival of $T$. urticae under solar radiation as well as the behavioral response. They escape from solar UV radiation by remaining on the underside of leaves (Sakai and Osakabe, 2010). Moreover, Fukaya et al. (2012) demonstrated the preferential exploitation of shaded area in Panonychus citri (McGregore), an upper surface user of host plant leaves (Fukaya et al., 2012). To understand how mites cope with a solar UVB radiation threat to their survival and fitness, it is critical to assess both physiological and behavioral adaptation to ambient UVB radiation as well as the mechanisms causing UV damage.

\section{Acknowledgements}

We thank participants in Panasonic Co. for providing and setting UVB lamp and a metal mask. This study was supported by a Grant-in-Aid for Scientific Research from the Ministry of Education, Culture, Sports, Science, and Technology of Japan (22380036).

\section{References}

Abbott, W.S., 1925. A method of computing the effectiveness of an insecticide. Journal of Economic Entomology 18, 265-267.

Aoki, S., 2011. Statistic Analysis Using R, Ohmsha, Tokyo, 320 p.

Barcelo, J.A., 1981. Photoeffects of visible and ultraviolet radiation on the two-spotted spider mite, Tetranychus urticae. Photochemistry and Photobiology 33, 703-706.

Connelly, S.J., Moeller, R.E., Sanchez, G., Mitchell, D.L., 2009. Temperature effects on survival and DNA repair in four freshwater cladoceran Daphnia species exposed to UV radiation. Photochemistry and Photobiology $85,144-152$.

Cywinska, A., Crump, D., Lean, D., 2000. Influence of UV radiation on four freshwater invertebrates. Photochemistry and Photobiology 72, 652-659. 
Dworkin, M., 1958. Endogenous photosensitization in a carotenoidless mutant of Rhodopseudomonas spheroids. The Journal of General Physiology 41, 1099-1112.

Fukaya, M., Uesugi, R., Ohashi, H., Sakai, Y., Sudo, M., Kasai, A., Kishimoto, H., Osakabe, M., 2012. Tolerance to solar ultraviolet-B radiation in the citrus red mite, an upper surface user of host plant leaves. Photochemistry and Photobiology, in press (doi: 10.1111/php.12001).

Grbić, M., Van Leeuwen, T., Clark, R.M., Rombauts, S., Rouzé, P., Grbić, V., Osborne, E.J., Dermauw, W., Ngoc, P.C.T., Ortego, F., Hernández-Crespo, P., Diaz, I., Martinez, M., Navajas, M., Sucena, É., Magalhães, S., Nagy, L., Pace, R.M., Djuranović, S., Smagghe, G., Iga, M., Christiaens, O., Veenstra, J.A., Ewer, J., Villalobos, R.M., Hutter, J.L., Hudson, S.D., Velez, M., Yi, S.V., Zeng, J., Pires-daSilva, A., Roch, F., Cazaux, M., Navarro, M., Zhurov, V., Acevedo, G., Bjelica, A., Fawcett, J.A., Bonnet, E., Martens, C., Baele, G., Wissler, L., Sanchez-Rodriguez, A., Tirry, L., Blais, C., Demeestere, K., Henz, S.R., Gregory, T.R., Mathieu, J., Verdon, L., Farinelli, L., Schmutz, J., Lindquist, E., Feyereisen, R., Van de Peer, Y., 2011. The genome of Tetranychus urticae reveals herbivorous pest adaptations. Nature 479, 487-492.

Ikegami, Y., Yano, S., Takabayashi, J., Takafuji, A., 2000. Function of quiescence of Tetranychus kanzawai (Acari: Tetranychidae), as a defense mechanism against rain. Applied Entomology and Zoology 35, 339-343.

Jurkiewicz, B.A., Buettner, G.R., 1994. Ultraviolet light-induced free radical formation in skin: an electron paramagnetic resonance study. Photochemistry and Photobiology 59, 1-4.

Kalthoff, K., 1975. Compensation for solar UV damage by solar radiation of longer wavelengths (Smittia spec., Chironomidae, Diptera). Oecologia (Berl.) 18, 101-110.

Kouwenberg, J.H.M., Browman, H.I., Cullen, J.J., Davis, R.F., St-Pierre, J.-F., Runge, J.A., 1999. Biological weighting of ultraviolet $(280-400 \mathrm{~nm})$ induced mortality in marine zooplankton and fish. I. Atlantic cod (Gadus morhua) eggs. Marine Biology 134, 269-284.

Macfadyen, E.J., Williamson, C.E., Grad, G., Lowery, M., Jeffrey, W.H., Mitchell, D.L., 2004. Molecular response to climate change: temperature dependence of UV-induced DNA damage and repair in the freshwater crustacean Daphnia pulicaria. Global Change Biology $10,408-416$.

Nahon, S., Porras, V.A.C., Pruski, A.M., Charles, F., 2009. Sensitivity to UV radiation in early life stages of the Mediterranean sea urchin Sphaerechinus granularis (Lamarck). Science of the Total Environment 407, 1892-1900.

Nozawa, H., Yamamoto, H., Makita, K., Schuch, N.J., Pinheiro, D.K., Carbone, S., Mac-Mahon, R.M., Foppiano, A.J., 2007. Ground-based observations of solar UV radiation in Japan, Brazil and Chile. Revista Brasileira de Geofísica 25, 17-25.

Nozawa, H., Yamamoto, H., Makita, K., 2010. Ground-based observations of solar UV radiation. ISATE2010: 4th International Symposium on Advances in Technology Education, 28-30 September 2010, Kagoshima, Japan, pp. 251-253.

Ohtuka, K., Osakabe, Mh., 2009. Deleterious effects of UV-B radiation on herbivorous spider mites: they can avoid it by remaining on lower leaf surfaces. Environmental Entomology 38, 920-929.

Onzo, A., Sabelis, M.W., Hanna, R., 2010. Effects of ultraviolet radiation on predatory mites and the role of refuges in plant structures. Environmental Entomology 39, 695-701.

R Development Core Team, 2009. R: A Language and Environment for Statistical Computing, Version 2.10.1. R Foundation for Statistical Computing, Vienna, Austria.

Riley, R.L., Kaufman, J.E., 1972. Effect of relative humidity on the inactivation of airborne Serratia marcescens by ultraviolet radiation. Applied and Environmental Microbiology 23, 1113-1120.

Sakai, Y., Osakabe, Mh., 2010. Spectrum-specific damage and solar ultraviolet radiation 
avoidance in the two-spotted spider mite. Photochemistry and Photobiology 86, 925-932.

Sakai, Y., Sudo, M., Osakabe, Mh., 2012. Seasonal changes in the deleterious effects of solar ultraviolet-B radiation on eggs of the twospotted spider mite, Tetranychus urticae (Acari: Tetranychidae). Applied Entomology and Zoology 47, 67-73.

Santos, C.D., 2005. Photoreactivation of ultraviolet-B damage in Tyrophagus putrescentiae (Acari: Acaridae) and Tetranychus urticae (Acari: Tetranychidae). International Journal of Acarology 31, 429-431.

Sinha, R.P., Häder, D.-P., 2002. UV-induced DNA damage and repair: a review. Photochemical and Photobiological Sciences 1, 225-236.

Suzuki, T., Watanabe, M., Takeda, M., 2009. UV tolerance in the two-spotted spider mite, Tetranychus urticae. Journal of Insect Physiology 55, 649-654.

Tachi, F., Osakabe, M., 2012. Vulnerability and behavioral response to ultraviolet radiation in the components of a foliar mite prey-predator system. Naturwissenschaften, in press (doi: 10.1007/s00114-012-0984-3).

Weber, S., 2005. Light-driven enzymatic catalysis of DNA repair: a review of recent biophysical studies on photolyase. Biochimica et Biophysica Acta 1707: 1-23.

Wübben, D.L., 2000. UV-induced mortality of zoea I larvae of brown shrimp Crangon crangon (Linnaeus, 1758). Journal of Plankton Research 22, 2095-2104. 


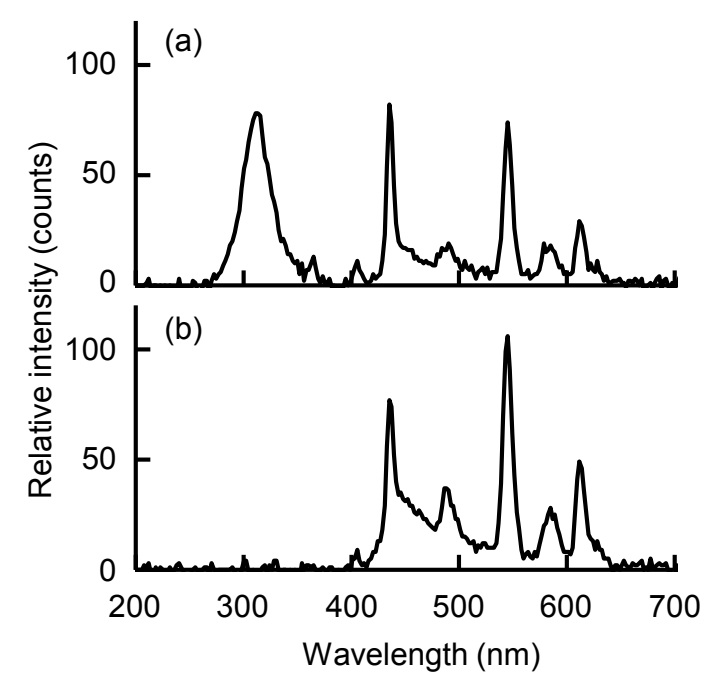

Fig. 1. Wavelength spectrums observed on experimental shelves under UVB irradiances of 0.31 (UVA+UVB: 0.45$) \mathrm{W} \mathrm{m}^{-2}$ (a), and $0 \mathrm{~W} \mathrm{~m}^{-2}$ (outside of the shelf frame) (b)

(a)

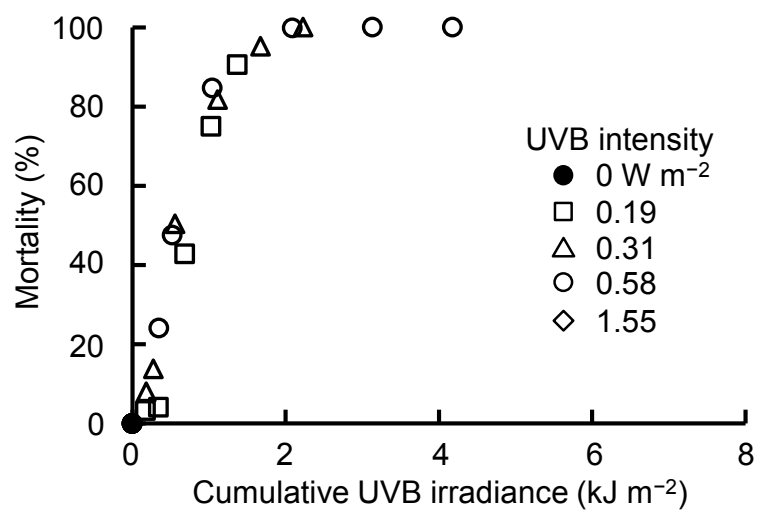

(c)

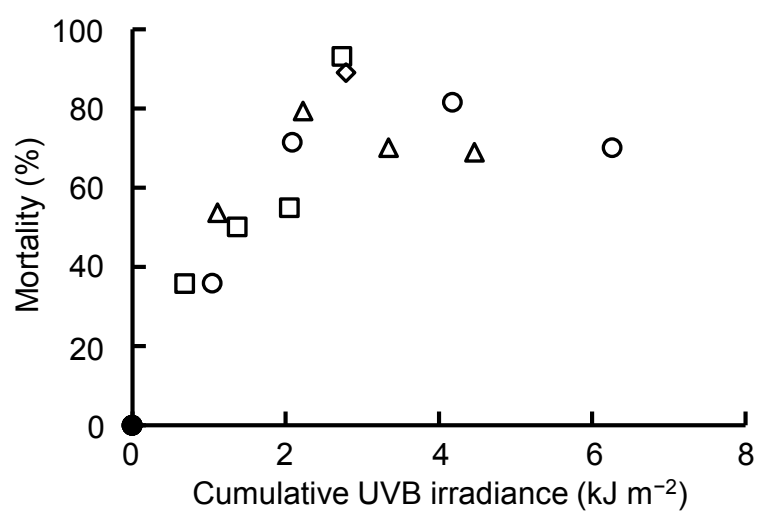

(b)

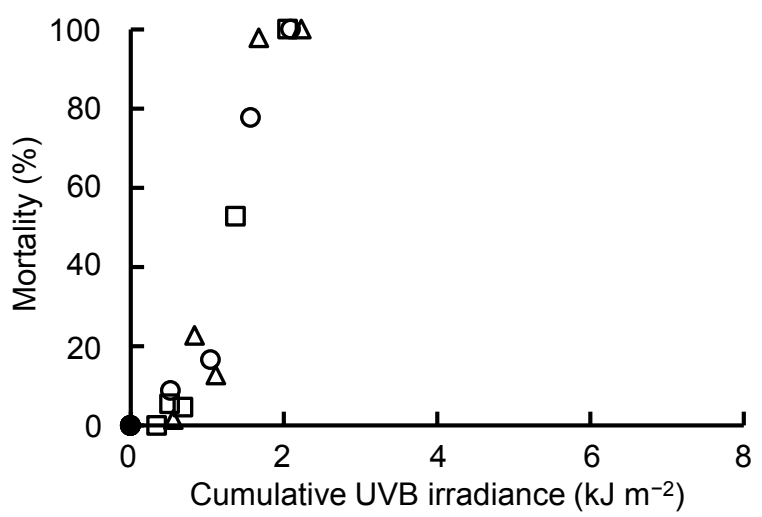

(d)

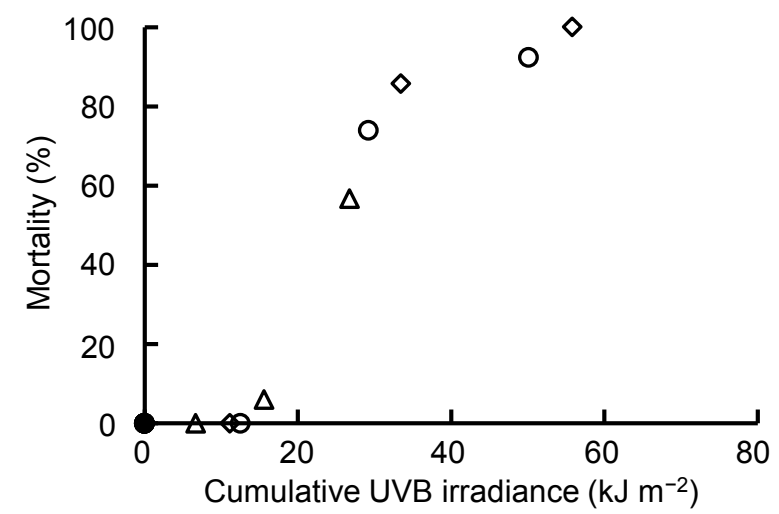

Fig. 2. Relationship between cumulative UVB irradiance and mortality of eggs (a), larvae (b), teleiochrysalis females (c), and adult females (d) after exposure to UVB radiation at different intensities and irradiation time length. 
Journal of Insect Physiology 59, 241-247 (2013)

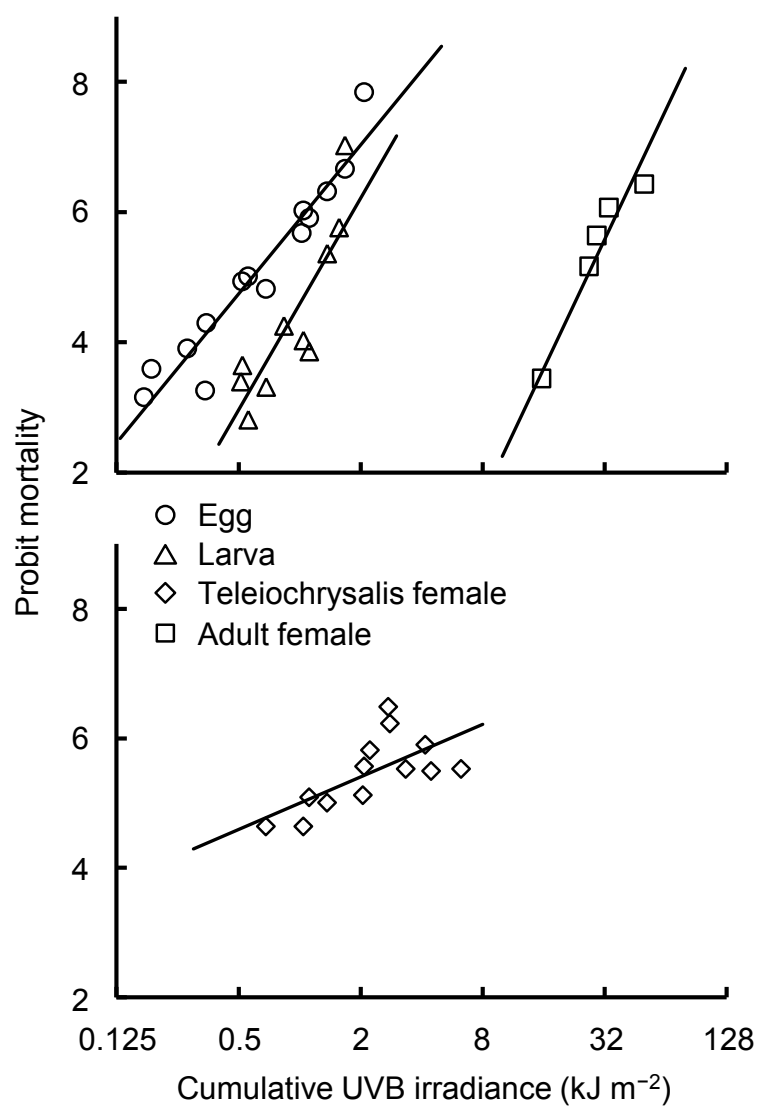

Fig. 3. Relationship between cumulative UVB irradiance and probit mortality of eggs, larvae, teleiochrysalis females, and adult females. Formulas and coefficients of determination $\left(\mathrm{R}^{2}\right)$ of the linear regression lines are shown in Table 1.

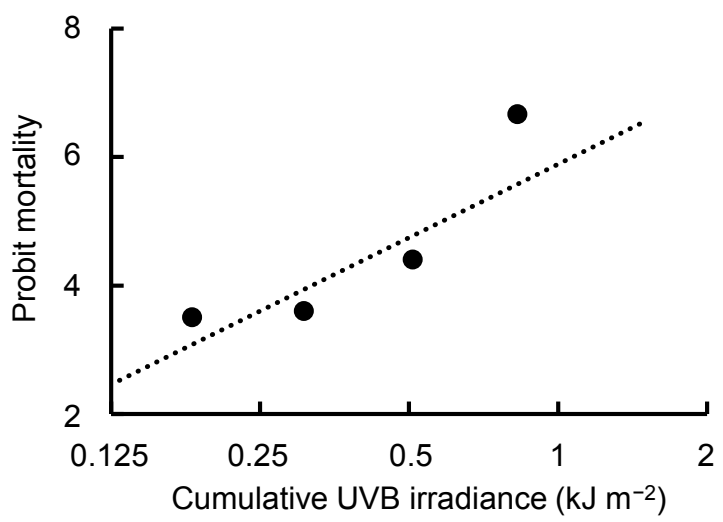

Fig. 4 Mortality of eggs exposed to UVB radiation at low intensity $\left(0.014-0.023 \mathrm{~W} \mathrm{~m}^{-2}\right.$; solid circles) and regression line of eggs exposed to UVB radiation at high intensity $(0.19-0.58 \mathrm{~W}$ $\mathrm{m}^{-2}$; dotted line; see Table 1). 
(a)

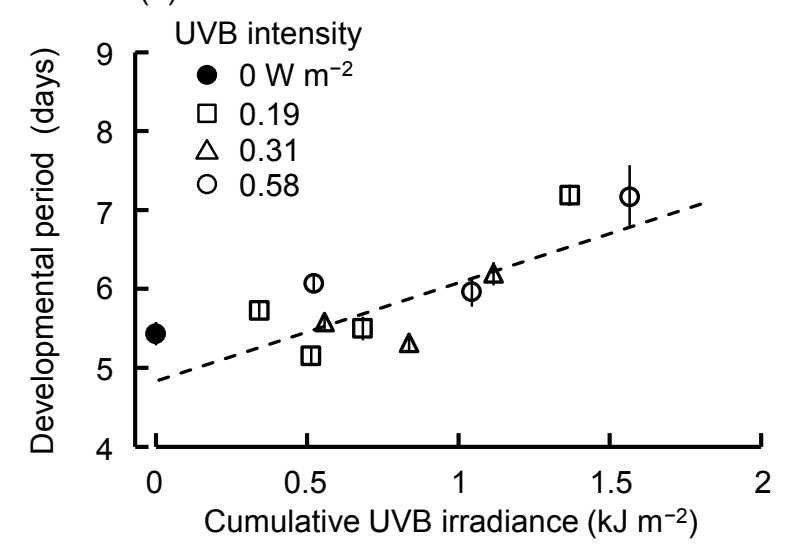

(b)

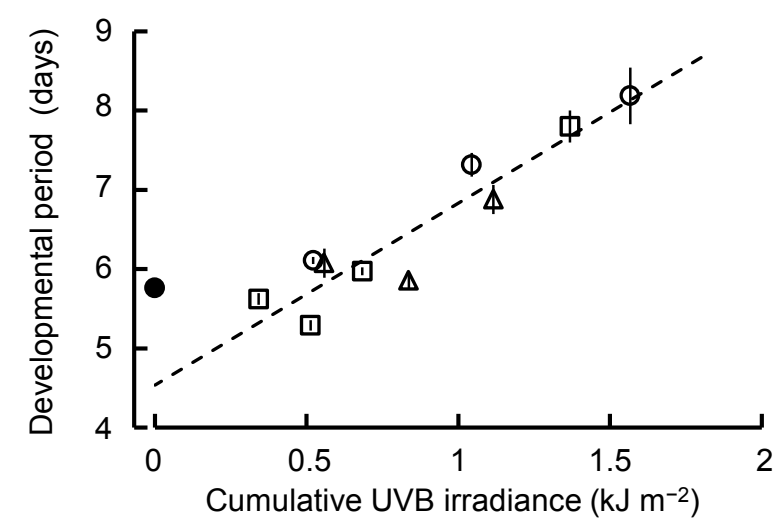

Fig. 5. Effects of cumulative UVB irradiance on developmental duration from larvae to adult emergence in males (a) and females (b). Vertical lines on plots represent standard errors. Broken lines in the figures show linear regression lines calculated using combined data sets over all UVB intensities, except controls (males: $y=1.2454 x+4.8320, R^{2}=0.6292, P=$ 0.006564; females: $\left.y=2.2946 x+4.5381, R^{2}=0.832, P=0.0003769\right)$.

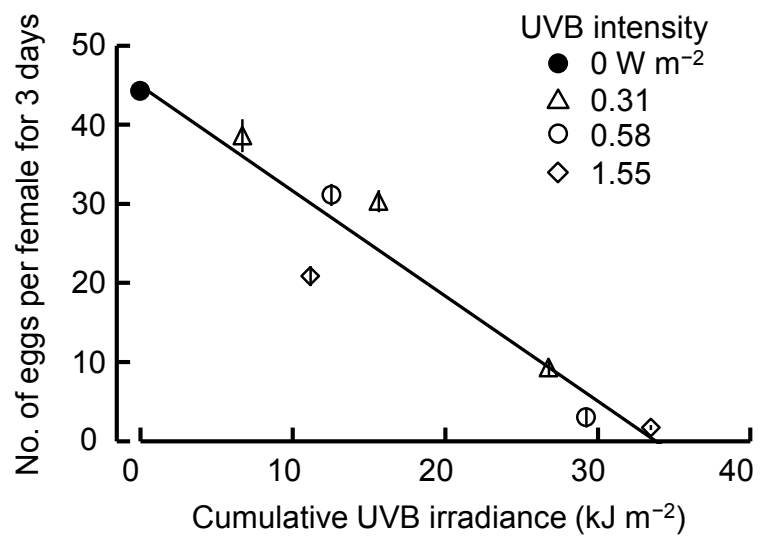

Fig. 6. Cumulative UVB irradiance and egg production by females that survived for 3 days after UVB treatment. Vertical lines on plots represent standard errors. The solid line shows the linear regression for the data set pooled over UVB intensities $\left(y=-1.3282 x+44.8954, R^{2}=\right.$ $0.906, P=0.0001686)$. Females surviving after exposure to $50.112 \mathrm{~kJ} \mathrm{~m}^{-2} \mathrm{UVB}$-radiation $(\mathrm{n}=$ 4 ) that did not lay eggs were excluded from the figure and the linear regression analysis. 
Journal of Insect Physiology 59, 241-247 (2013)

Table 1. Linear regression of probit mortality on cumulative UVB irradiance $\left(\mathrm{kJ} \mathrm{m}^{-2}\right)$ and $\mathrm{LD}_{50}$ values in eggs, larvae, teleiochrysalis females, and adult females

\begin{tabular}{lccccc}
\hline $\begin{array}{l}\text { Developmental } \\
\text { stage }\end{array}$ & Regression formula & $\mathrm{R}^{2}$ & P value & $\begin{array}{c}\mathrm{LD}_{50} \\
\left(\mathrm{~kJ} \mathrm{~m}^{-2}\right)\end{array}$ & $\begin{array}{c}95 \% \text { confidence } \\
\text { interval }\end{array}$ \\
\hline Egg & $y=1.6485 \ln (x)+5.8904$ & 0.9181 & $4.346 \times 10^{-8}$ & 0.58 & $0.51-0.67$ \\
Larva & $y=2.3492 \ln (x)+4.5864$ & 0.7082 & 0.001392 & 1.19 & $0.94-1.52$ \\
Teleiochrysalis & $y=0.5864 \ln (x)+4.9956$ & 0.3944 & 0.01277 & 1.01 & $0.48-2.10$ \\
Adult & $y=2.866 \ln (x)-4.352$ & 0.8897 & 0.01036 & 26.12 & $21.64-31.52$ \\
\hline
\end{tabular}

a $y$ and $x$ represent probit mortality and logarithmic cumulative UVB irradiance, respectively

Table 2. GLM analysis for applicability of reciprocity to UVB irradiation at low intensity $\left(0.014-0.023 \mathrm{~W} \mathrm{~m}^{-2}\right)$ [probit mortality $\sim \ln (x)+\mathrm{UVB}$ intensity (high/low)]

\begin{tabular}{lllll}
\hline & Coefficient & $\mathrm{SE}$ & $t$-statistic & $\operatorname{Pr}(>|\mathrm{t}|)$ \\
\hline (Intercept) & 5.9138 & 0.1448 & 40.839 & $<2 \times 10^{-16}$ \\
$\ln (x)^{\mathrm{a}}$ & 1.6972 & 0.1506 & 11.270 & $1.01 \times 10^{-8}$ \\
UVB intensity (low) & 0.2201 & 0.2749 & 0.801 & 0.436 \\
\hline
\end{tabular}

${ }^{\mathrm{a}}$ Logarithmic cumulative UVB irradiance 